\title{
Fysisk aktivitet - en del av sunda kostvanor. Leder arbetet av en Nordisk arbetsgrupp till aktioner?
}

\author{
[Physical activity - a part of healthy eating: Will the \\ recommendations of a Nordic working group lead to actions?]
}

\author{
Mikael Fogelholm
}

UKK institutet, Tammerfors, POB 30, 3350 I Tampere, Finland.

\begin{abstract}
The present Nordic Nutrition Recommendations mainly regard physical activity as a part of daily energy expenditure. The health effects of adequate daily activity are covered only briefly and the potential synergism with a prudent diet is almost totally forgotten. A Nordic working group has suggested that the new Nordic Nutrition Recommendations (to be presented in 2004) should try to integrate physical activity as a natural part of healthy eating. This pioneering exercise is interesting and it is hoped that an integration of these two important lifestyles might even improve the acceptance and efficacy of the recommendations. In a way, the clearly longer history and tradition of nutrition recommendations may possibly be used to promote physical activity. The present atmosphere to include physical activity in nutrition recommendations seems to be good at least in Finland, where several recent statements, recommendations and action plans have included physical activity.
\end{abstract}

Keywords: diet, physical activity, recommendations.

De Nordiska Näringsrekommendationerna (1) lyfter fram fysisk aktivitet i kapitlet "Energi" med följande synpunkter: "Adekvat fysisk aktivitet är en viktig del i en hälsosam livsstil för hela befolkningen. - För att få bästa effekt bör motionen vara regelbunden. - Vuxna bör uppmuntras att öka den regelbundna fysiska aktiviteten så att den motsvarar minst $1 / 2$ timme per dag med aktiviteter av moderat intensitet - Mer ansträngande aktiviteter såsom lätt jogging, cykling, olika bollspel (tennis, fotboll m.m.) och simning kan ge ytterligare hälsomässiga fördelar.”. Dessa synpunkter är väsentliga och de följer de senaste internationella rekommendationerna (2), men i sin helhet fyller de en ytterst anspråkslös del i näringsrekommendationerna.

Denna artikel är en del $\mathrm{i}$ arbetet med att ta fram fysisk aktivitet i de nya Nordiska Näringsrekommendationerna. Arbetet har tidigare refererats i Scandinavian Journal of Nutrition (3) och en fullständig sammanfattning av ett seminarium i Lahtis (4) har publicerats. Dessutom ges en översikt av de nya finska rekommendationer, som har fysisk aktivitet som en viktig komponent.
Fysisk inaktivitet, kanske i större utsträckning än dåliga kostvanor, är ett problem i de nordiska länderna. Enligt tillgänglig data har antalet individer som ägnar sig at regelbunden motion ökat något under de senaste artiondena, men det finns anledning att tro att den totala aktiviteten, till exempel uttryckt i daglig energiförbrukning, har minskat. Det huvudsakliga skälet för en påtaglig nedgång i den totala aktiviteten är en minskning av de vardagliga, arbets- och fritidsrelaterade aktiviteterna. Kost och fysisk aktivitet skall inte ses som alternativ till varandra, utan som komplement som båda bidrar till hälsa, kanske särskilt i kombination. Därför borde rekommendationer för fysisk aktivitet och kost inte behandlas var för sig.

Seminariet i Lahtis (4) ledde till en konkret handlingsplan: arbetsgruppen, som förbereder de nya Nordiska Näringsrekommendationerna (kommer ut år 2004) kompletterades av två experter på relationer mellan fysisk aktivitet, kost och hälsa. Fysisk aktivitet far ett eget kapitel, och vidare kommer fysisk aktivitet att behandlas i kapitel om fetma, hjärt- och kärlsjukdomar, blodtryck och 
osteoporos. Syftet är att klart redogöra hur nära effekterna av fysisk aktivitet och kost är sammankopplade

\section{Utgangspunkter för rekommendationer}

Det finns två olika utgångspunkter för rekommendationer: Rekommendationerna kan endera vara beteende- eller sjukdomsbaserade. Beteendebaserade rekommendationer har ett hälsobeteende, t.ex. kost, fysisk aktivitet eller rökning, som utgångspunkt. Kostrekommendationerna är ett klassiskt exempel på beteendebaserade rekommendationer. De första kostrekommendationerna utgavs i Norge âr 1954 och serien med samnordiska rekommendationer började år 1980 (1). Problemet med beteendebaserade rekommendationer är att man oftast glömmer att det finns kompletterande beteenden såsom fysisk aktivitet.

Sjukdomsbaserade rekommendationer brukar omfatta olika hälsobeteenden, med anknytning till sjukdomen eller med förebyggande av sjukdomen. Rekommendationerna brukar betona både förebyggande atgärder och behandling, samt ge rekommendationer för riskgrupper, patienter samt den "stora allmänheten". Typiska sjukdomsbaserade rekommendationer finns för t.ex. förebyggande av hjärt- och kärlsjukdomar, typ II diabetes, fetma, cancer och osteoporos. Precede-Proceed modellen (5) har varit förebild. I hälsofrämjande arbete beaktas såväl förändringar i den fysiska som den sociala miljön.

\section{Nya rekommendationer för fysisk aktivitet $i$ Finland}

Det är märkbart att relativt många nationella rekommendationer i Finland under de senaste två åren har fysisk aktivitet som en väsentlig komponent eller t.o.m. har fysisk aktivitet som en utgångspunkt. En annan inressant och uppmuntrande detalj är att vetskapen om hälsoeffekten av moderat aktivitet och så kallad vardagsaktivitet syns i rekommendationerna.

“Åtgärdsplan för befrämjande av finländarnas hjärthälsa" utgavs 1999 av Social- och hälsovårdsministeriet (6). Publikationen är byggd på en bred konsensuspanel, som sammanställde åtgärdsplanen med förslag till centrala metoder för att förbättra kostvanor, öka fysisk aktivitet, minska rökning, minska psykiska och sociala riskfaktorer samt öka människans ansvar för att befrämja sin egen hälsa. Kapitlet om fysisk aktivitet ger rekommendationer för staten, kommunerna, skolorna, idrotts- och motionsorganisationerna, arbetsgivarna och organisationerna som distribuerar forskningsrön. Åtgärdsplanen innehåller både synpunkter på hur mycket och på vilket sätt fysisk aktivitet befrämjar hjärthälsa samt om hur man kan stödja främjande av ökad fysisk aktivitet. Både kost och motion behandlas, men i omfång behandlas kostvanorna på 19 sidor och fysisk aktivitet på endast 7 sidor.

"Utvecklingsprogram för förebyggande och behandling av diabetes, 2000-2010" utgavs av Diabetesförbundet år 2000 (7). Tyngdpunkten i programmet riktas mot hur sjukdomar bör behandlas, medan strategi och atgärder för förebyggande av diabetes behöver utvecklas. Både ökad fysisk aktivitet och förändrade kostvanor nämns som preventiva atgärder, men endast kort och ytligt. Programmet saknar konkreta rekommendationer om hur mycket fysisk aktivitet som behövs för att förebygga typ II diabetes och hur man kan stödja främjande av aktivitets- och kostvanor. En arbetsgrupp har fortsatt arbetet med förebyggande av typ II diabetes. Senaste forskningsrön frân t.ex. Finland (8) har klart visat att det är möjligt att minska förekomsten av typ II diabetes bland riskindivider med relativt små förändringar i kost, motion och vikt.

Social- och hälsovârdsministeriet publicerade rapporten "Hälsomotion - lokala rekommendationer" år 2000 (9). Rekommendationerna innehåller förslag till centrala utgångspunkter, målsättningar och målgrupper för hälsomotionsverksamheten på lokal nivå. Rekommendationer ges separat för kommunerna, för primärvården och om hälsomotionstjänster. Idén bakom rekommendationerna är, att det är viktigt att så många kommuninvånare som möjligt kan garanteras möjligheter till daglig motion $i$ en trygg miljö som är lätt att nå. Korta rekommendationer ges för olika målgrupper. Det är märkbart hur breda rekommendationerna är - inte bara omfattande utbildning, utan ocksa förslag till förändringar av miljön.

En följd av tvärsektoriellt tänkande är att kommunikationsministeriet (som i Finland har ansvaret för trafikfrågorna) har kommit ut med ett förslag till cykelpolitiskt program (10) och ett annat förslag till gångpolitiskt program (11). Syftet med ovan nämnda program är att främja atgärder som kan öka gång- och cykeltrafikens popularitet samt förbättra gång- och cykeltrafikmiljöns trivsamhet, säkerhet och tillgänglighet. Rekommendationer ges 
både till nationella och lokala åtgärder - på det sättet närmar sig kommunikationsministeriets rekommendationer de tidigare nämnda råden för lokala hälsomotionsarrangörer (9).

Social- och hälsovårdsministeriet har tillsatt en kommission för utvecklande av hälsomotion. I slutet av ar 2001 kom komissionen ut med ett betänkande, som offentligt publicerades âr 2002 (12). Komissionen föreslår att man fram till år 2005 använder ca 3,4 miljoner euro mer en hittills per år för hälsobefrämjande motion.

\section{Hur leder rekommendationerna till aktion?}

Rekommendationer för kost i Norden har en lång historia (1). Olika rekommendationer med fysisk aktivitet har en kortare historia, men aktiviteten inom området är just nu hög.

Rekommendationerna skall vara baserade på ett verkligt behov på vetenskaplig grund. Åtgärderna kan vara ambitiösa, men bör vara realistiska. Helst skall alla berörda parter vara med i förarbetet med rekommendationerna. Spridningen skall vara tillräckligt bred och den skall stödjas av t.ex. mass media, föreläsningar och andra kampanjmetoder. Rekommendationerna skall identifiera populationsgrupper, t.ex. enligt alder, risk för sjukdom eller social bakgrund, som sedan blir objekt för den riktade åtgärden. Förebyggande råd mot hjärt- och kärlsjukdomar, typ II diabetes, vissa typer av cancer (bröst, tjocktarm) och fetma innehåller snarlika komponenter. Aktionsprogrammen bör få tillräckligt finansiellt stöd och expertstöd. Även om man vill ha nationellt inflytande bör ändå resurserna riktas till "bred lokalnivå", t.ex. till kommun eller länsnivå. Resultaten av alla aktionsprogram skall följas upp med vetenskaplig noggrannhet. Den feedback man får skall sedan styra programmet vidare.

\section{Referenser}

1. Sandström B, Aro A, Becker W, Lyhne N, Pederson JI, Thórsdottir I: Nordiska näringsrekommendationer 1996. Köpenhamn: Nordiska Ministerrådet 1996:28.
2. Pate RR, Pratt M, Blair SN, Haskell WL, Macera CA, Bouchard C, Buchner D, Ettinger W, Heath GW, King $\mathrm{AC}$ et al: Physical activity and public health. A recommendation from the Centers for Disease Control and Prevention and the American College of Sports Medicine. JAMA 1995;273:402-7.

3. Fogelholm M, Kolset SO, Rasmussen L, Sjöström M, Yngve A: Physical activity - an essential part of dietary recommendations? Scand J Nutr 2000;44:69-70.

4. Fogelholm M, ed. Physical activity: A part of healthy eating. Report from a Nordic Seminar, Lahti, 2001. TemaNord 2001;554. Copenhagen: Nordic Council of Ministers 2001.

5. Green LW, Kreuter MW. Health promotion planning: an educational and environmental approach. Mountain View, CA: Mayfield, 1991

6. Social- och hälsovårdsministeriet. Åtgärdsplan för befrämjande av finländarnas hjärthälsa. Publikationer 1999:3. Helsingfors: Social- och hälsovårdsministeriet 1999.

7. Diabetesliitto. Diabeteksen ehkäisyn ja hoidon kehittämisohjelma 2000-2010. Tampere: Diabetesliitto 2000 (Diabetesförbundet. Utveckling av behandling och förebyggande av diabetes; på finska).

8. Tuomilehto J, Lindström J, Eriksson JG et al: Prevention of type 2 diabetes mellitus by changes in lifestyle among subjects with impaired glucose tolerance. N Engl J Med 2001;344:1343-50.

9. Social- och hälsovårdsministeriet. Hälsomotion - lokala rekommendationer. Sammandrag. Publikationer 2000:20. Helsingfors: Social- och hälsovårdsministeriet 2001.

10. Kommunikationsministeriet. Ny emfas på cykling förslag till cyklingpolitiskt program. Kommunikationsministeriets publikationer 5/2001. Helsingfors: Kommunikationsministeriet, 2001 (sammandrag på svenska).

11. Kommunikationsministeriet. Gångtrafiken som en del av trafikpolitiken - förslag till gångpolitiskt program. Kommunikationsministeriets publikationer 6/2001. Helsingfors: Kommunikationsministeriet, 2001 (sammandrag på svenska).

12. Social- och hälsovårdsministeriet. Betänkande av komissionen för utvecklande av hälsomotion. Kommittébetänkande 2001: 12. Helsingfors: Social- och hälsovårdsministeriet, 2001 (sammandrag på svenska).

Mikael Fogelholm

UKK institutet, Tammerfors, POB 30, 3350 I Tampere, Finland. E-mail: mikael.fogelholm@uta.fi 